
\title{
is Research Square \\ What Older Patients and their Relatives Say is Important During Acute Hospitalisation: A Qualitative Study
}

Nina Mickelson Weldingh ( $\square$ nina.mickelson.weldingh@ahus.no)

Akershus University Hospital

Marit Kirkevold

OsloMet - Oslo Metropolitan University

\section{Research Article}

Keywords: Cognitive impairment, Age-friendly hospital, Patient experiences, Older patients, Family involvement, Acute hospitalisation, Acute care

Posted Date: November 19th, 2021

DOI: https://doi.org/10.21203/rs.3.rs-1063415/v1

License: (c) (i) This work is licensed under a Creative Commons Attribution 4.0 International License.

Read Full License 


\section{Abstract}

\section{Background:}

Due to the growing elderly population across the world, providing safe and effective care to older people is an increasing concern. Hospitals need to adapt to ensure high-quality care for older patients. Several age-friendly frameworks and models aiming at reducing risks and complications have been promoted. However, care for the elderly must be based on the patients' reported needs, and relatives are often an important part of the patients' resources. The primary aim of this study was to explore elderly patients' and their relatives' experiences of acute hospitalisation and determine what is important for them to experience a good hospital stay.

Methods: This study has a qualitative research design in which patients aged 75 years or older and their relatives were interviewed during their acute hospitalisation. The study was conducted at two medical bed wards at a large university hospital in Norway. All interviews were thematically analysed.

Results: Four major themes were identified in patients' and relatives' descriptions of how they experienced the hospital stay and what was important for them during the hospital stay: being seen and valued as a person, individualised care, patient-adapted communication and information, and collaboration with relatives. The themes span both positive and negative experiences, reflecting great variability in the experiences described.

Conclusions: The results underscore how small things matter in relation to how we meet and communicate with older patients and their relatives. How health personnel get to know the patient's individual values, need for care, information and involvement of relatives affects their experiences of the hospital stay.

\section{Background}

The number of elderly people in the world is growing rapidly, with an estimated doubling of persons over 60 years between 2015 and 2050 (1). Comorbidity, polypharmacy and impaired physical and cognitive functioning are common in old age, and older patients require hospitalisation more frequently. One-third of older patients presenting in the hospital emergency department have some type of cognitive impairment $(\mathrm{Cl})(2,3)$. Dementia and $\mathrm{Cl}$ are significant risk factors for developing delirium and other complications during a hospital stay (4-6). Furthermore, older patients are more vulnerable to complications and poor outcomes because of accumulating frailty and disability $(7,8)$.

Thus, providing safe and effective care to older people is an increasing concern, and hospitals need to adapt to ensure high-quality care for older inpatients. Patient-centred care has been the recommended approach for elderly patients with cognitive impairment; however, this has proven challenging to comply with in modern hospital settings with busy environments and short lengths of stay (9). To overcome this challenge, several models have been designed to provide care to older adults in acute hospital care (10- 
12). Such 'age-friendly hospitals' (AFH) aim to establish systems and evidence-based practices that support high-quality care for older patients. Some of the early contributions to age-friendly hospital care, including the 'Elder-Friendly Hospital' programme (13), 'The Hospital Elder Life Program' (HELP) (14) and the 'Acute Care for Elders' (ACE) strategy (15), focused primarily on the recognition of risks and prevention of adverse consequences. The World Health Organization (WHO) proposed a set of age-friendly principles in 2008 , seeking to optimise care for elderly patients. These principles also took into account the older patients' needs and satisfaction with care. Subsequently, the Institute for Health Improvement (IHI) developed the Age-friendly Health Systems Model framework (4Ms framework), which emphasises four core elements: what matters, medications, mobility and mentation (10).

Although several studies describe the development of such models (15-19), implementation has been limited, and less emphasis has been put on exploring older patients' and their relatives' experiences with acute hospital settings and their perspectives on what matters to them during the hospital stay.

Previous studies of older patients' and relatives' experiences with acute hospitalisation have described the hospital stay as a challenging time for patients, especially for those with cognitive impairment, due to the narrow focus on the somatic cause of admission and insufficient emphasis on the patient's individual needs for support and care (20-23). Patients' needs for social contact, dignity and respect are often ignored, resulting in patients feeling devalued $(22,23)$, and their experiences are influenced by the staff's communication practices and degree of family involvement (24-26). Relatives and informal carers desire to be involved in the care but often experience a loss of control as they are devalued by clinicians (21, 25-28). While there are many studies describing patients' experiences with acute care, most research has focused on older patients with dementia; thus, experiences and needs are influenced by dementia severity. While many older patients have complex needs and may have different forms of cognitive impairment that have not yet been formally diagnosed, it is important to include older patients more generally to capture their experiences from a broader perspective. Furthermore, few studies capture both patients' and relatives' experiences of the same hospital stay. Consequently, there is a need to gain more knowledge about elderly patients' and their relatives' experiences during a hospital stay. This knowledge may guide health personnel and policymakers in designing health services that facilitate more agefriendly care for older patients.

\section{The aim of the study}

This study aimed to explore how elderly patients and their relatives experience acute hospitalisation and what they emphasise as important for them during the hospital stay.

\section{Methods}

\section{Design}


This study had a qualitative research design, using qualitative interviews to explore how older patients with complex needs and different forms of cognitive impairment and their relatives experienced their acute hospital stay. A qualitative methodology is well-suited for exploring people's individual views and experiences while considering the descriptions as part of a social context, such as an acute care setting (29).

\section{Setting and participants}

This study is part of a larger research study aiming to optimise the care of patients with cognitive impairment (including both dementia and cognitive impairment). The study took place in two medical wards (a pulmonary and a cardiac ward) at a large acute-care hospital in Norway with a catchment area of 600,000 inhabitants.

Potential participants were patients 75 years of age or older who were admitted to the pulmonary or cardiac bed wards for acute medical illness between October 2018 and December 2019. Patients with sufficient physical health to participate in interviews were recruited by clinical research nurses working on the two wards. The participants had to be cognitively able to understand the study, sign an informed consent form, and take part in an interview in Norwegian or English. The patients decided whether they wanted a relative present during their interview. Patients were invited to participate by being visited in the ward or through a telephone call. As we aimed to capture the range of experiences and views among elderly patients during an acute hospital stay, we sought to include participants who varied in terms of age, gender, severity of cognitive impairment and relation to their relative (spouse, parent, etc.). A total of 59 interviews were completed, including 33 with patients and 27 with relatives. Sample characteristics are presented in Table 1.

\section{Table 1}

Characteristics of the sample 
Gender, n (\%):

Female:

Male:

Ag, years min-max (median)

Relation of relative, $\mathrm{n}(\%)$ :

Husband/Wife:

Daughter:

Son:

Niece/nephew:

$\begin{array}{lll}14(23.3) & 21(35.0) & 35(58.3) \\ 19(31.6) & 6(10.0) & 25(41.6)\end{array}$

75-94 (84.4)

9 (33.0)

$12(44.0)$

5 (18.5)

$1(0.3)$

\section{Data collection}

Data were obtained using individual qualitative interviews. Each participant was interviewed once during the hospital stay for 20-90 minutes. The interviews focused on their immediate experiences with the hospital stay. Previous research (23) has shown that people with cognitive impairment can express their own experiences, views, thoughts and feelings related to the "here-and-now" situation. Patients were also asked to give their suggestions on how to improve their hospital stays. The interviews were conducted based on a thematic interview guide. Interviews with the relatives were conducted close to discharge from the ward, or as a telephone interview shortly after discharge. The interviews focused on the patient's experiences related to their hospital stays, including both positive and negative experiences. They were also asked to give their suggestions on how the hospital stay could have been improved to provide adequate care for patients with cognitive impairment. All interviews were recorded using a tape recorder and transcribed verbatim by Mrs. NMW. Field notes were taken during the interviews for reference during coding. The study was conducted by two female researchers with nursing backgrounds and research training at the master's and PhD levels. One has extensive experience with qualitative methods and research on geriatric nursing care (MK), while the other has extensive experience in the acute care of the elderly (NMW).

\section{Data analysis}

All interviews were transcribed by NMW. All data were then analysed using the six-phase approach to thematic analysis described by Braun and Clarke (30). This is a method for identifying, analysing and reporting patterns in qualitative data, and the approach has been widely used and accepted as robust 
across a wide range of disciplines. In the first phase, both authors (NMW and MK) read through the entire dataset to get an initial understanding of the data. NMW then reviewed all data and developed codes that captured the patients' and their relatives' positive and negative experiences related to the hospital stay. These codes were reviewed by co-author MK to ensure agreement between the codes and the data. Initial differences were discussed until a consensus was reached. An inductive approach was followed in which NMW and MK independently reviewed the data index for each code and then categorised the codes into potential themes. The themes were compared and discussed in terms of relevance to the research questions until a consensus was achieved. The themes were then refined to ensure that each initial theme was distinct from the other themes, while the data within the themes cohered together meaningfully. Finally, the titles of the themes were discussed back and forth to be as concise as possible. We have used the consolidated criteria for reporting qualitative studies (COREQ) (31) when reporting this study.

\section{Ethical considerations}

Ethical approval for the study was obtained from the local officer for data protection and the Regional Committee for Medical and Health Research Ethics in Norway (2018/666). All patients were asked to give written consent for the use of data collected in this project.

\section{Results}

We identified four major themes (Fig. 1.) that capture what patients and their relatives experienced as important for them during the acute hospital stay: being seen and valued as a person, individualised care, patient-adapted communication and information, and collaboration with relatives. The themes span both positive and negative experiences, reflecting great variability in the experiences described. The material can be understood as a continuum between the two opposites of positive and negative experiences. By positively emphasising these four factors, patients experienced being met and respected for who they were and their own needs, which contributed to a feeling of predictability and safety for both patients and relatives. If, on the other hand, these were not present, the hospital stay was experienced as unpredictable and, for some, unsafe. The negatively 'coloured' experiences contributed to patients and relatives experiencing not having their needs met or feeling unworthy, which led to disappointment and even resentment. In the following, the four themes are delineated in further detail.

\section{Being seen and valued as a person}

The patients' and relatives' experiences emphasised the importance of each patient being seen and recognised as a person who is valued and met with respect, honesty, kindness and compassion, and not treated as a 'commodity'. A patient described it as a form of honest kindness:

'It is the kindness and ... I want to emphasise, the honest kindness. There is a difference... Kindness can be acquired quite easily, but the honest kindness is the one you see in people [here]'. Patient (P)1 
Several aspects of the hospital stay influenced the experiences, colouring them as primarily negative or positive. The relatives having positive experiences during the hospitalisation valued that the health personnel communicated directly to the patients, as this contributed to each patient feeling respected as a person. There was also a recognition that 'being seen and valued as a person' was closely connected to how much time the health personnel spent with the patient. Both patients and relatives describing positive experiences found it reassuring that the health personnel visited the patient often, often outside of routine tasks, and spent time listening to what the patient had to say, even though they were in a hurry and had many other patients to look after:

'I have not seen anything like it. I have been so safe, I have not been anxious for an hour, they have been here so often'. P2

In a way it is always like: "Here is the leash!"-coming by and [saying]: "Just pull this, I will come again". And if she does not pull the bell, they will come by anyway. I think it is absolutely fantastic how she has been followed up; an incredible number of skilled people work there'. Relative (R)1

These patients and relatives generally expressed great trust in, and respect for, the health personnel for doing a great job despite limited available time. Even though they recognised the constant bustle in the hospital ward, they felt safe and taken care of. The following quotes illustrate the sentiments among these participants:

'They run several kilometres a day and are doing the best they can. You cannot ask for more'. P3

'I think they are completely unique. Ring this bell and they will come right away... if they are not somewhere else. Sure, they cannot be everywhere at once'. P4

Furthermore, being taken seriously and listened to were closely linked to positive experiences. Both patients and relatives expressed the importance of being closely followed up and assured by the doctor that they were doing everything they could for the patient and were not giving up on them just because they were old:

'It is important...that she is taken seriously, even though she is almost 90 years old....I think that is important. You are not getting scooped up in a corner because you are too old, and I think that is very good.'R2

In contrast to the positive experiences of being seen and valued, this sample also reflects negative experiences in relation to feeling seen and valued as a person. Several patients and relatives felt that the care was not consistent. Their experiences varied greatly depending on the staff members who cared for them. They described large differences in helpfulness and understanding among the staff. Some of the patients expressed that when you are a vulnerable patient unable to speak up for yourself, you are at the mercy of the person you meet, which ought not to be the case: 
'When you wear this gown, you are put together with all the others. They do not greet one, and there are many who... they just shuffle past and look straight ahead'. P5

Many patients expressed feeling lonely and bored during the hospital stay, and that their psychological and social needs were often not met. Some patients would have loved to take a walk outside the patient room, either to talk to other co-patients or just to see something other than the walls inside the patient room. However, they experienced that no one saw them or their needs; the staff was busy and concerned with medical issues and task-oriented care. If anyone happened to come into their room, it was just because they had some routine tasks to accomplish. This led to doubts about whether the staff was able to provide adequate care at all:

'I think both me and my mother experience it as an assembly line. There is no care in those who work there. You are just a number in the line, and everything goes on autopilot and then out...done with you'. R3

Furthermore, when patients experienced being left alone in the patient room and felt that no one had time to look after them, they often felt totally ignored and unworthy:

'They just drive you into a "hole", and then there you go... just lie here until we have time for you'. P6

One patient expressed that she thought the staff was tired of her; when she called the bell, she was told that she had to wait because they had many others to take care of. This left the patient with feelings of anger, being a burden and greater vulnerability:

'I know there are others here....but when I'm in pain, I need help...'. P6

\section{Individualised care}

The patients and the relatives emphasised that one of the most important aspects contributing to a positive hospital stay was receiving help with their individual problems and knowing that something was being done and that they experienced getting better:

'I have had such a good time during my hospital stay, I could not wish for more. The nurses, doctors, everyone ... they got me on my feet'. P2

Relatives appreciated when staff were well prepared and well informed about patients' care needs. This was especially important for patients with cognitive impairment. The relatives expressed satisfaction with the health personnel's focus on the patients' wellbeing and creating a calming and less stressed environment so the patient felt safe and calm even though they were in an unfamiliar environment. As one relative explained:

'I think a lot is good... they know that my dad has a hearing aid in his right ear, they know that they have to speak loud and clear. They know they have to look at him when they talk to him. And they ask questions back to him, to hear if he has understood correctly. In other words, they have read the patient 
journal and they know what they are supposed to do in relation to communication and how the patient is doing'. R4

Some relatives experienced that the care focused primarily on the diagnosis of relevance for the unit in which the patient was admitted, rather than the person as a whole human being. These individuals experienced that staff had special competence in their particular fields (e.g., heart or lung diseases), but not the competence to address other matters, which is necessary in relation to care of the elderly. For example, patients and relatives articulated that sometimes patients with cognitive impairment have problems communicating their own needs and that they often misunderstand things. Thus, to help these patients with their individual needs, the health personnel must have knowledge on how to adapt care to patients with cognitive impairment:

'You have to try to treat each patient differently based on each diagnosis, and if there are several diagnoses, they must try to see the whole... like how can we try to do the best for this patient? But it is not so easy to do something for a patient who is not quite able to say what he wants.' R5

Relatives articulated that the staff was not aware of how serious the patient's cognitive impairment and memory loss actually was and the serious consequences it could lead to if the health care personnel were not careful enough. Sometimes the patients can say no to a question when they actually mean yes-or they may know what they want to tell, but they do not remember the words and do not manage to express it. The patients expressed that they sometimes felt stupid and did not always manage to think clearly. One patient explained that his tongue did not always cooperate and that it was difficult to express himself. Relatives of patients with cognitive impairment often experienced that the patients did not question anything, and sometimes they did not manage to ask for painkillers. Thus, they could be suffering from pain for a long period if the health personnel did not help them to convey their needs:

'Even though you have dementia, and may not manage to express yourself, you still feel pain'. R6

Furthermore, patients with cognitive difficulties often forgot to ring the bell when they needed help or forgot that they could not walk, thereby needing supervision more often than other patients.

\section{Patient-adapted information and communication}

There was some variation in how patients and relatives experienced receiving the information they needed. Positive experiences of the hospital stay were connected to relatives and patients having adequate and patient-adapted information during the hospital stay. The patients wanted the health personnel to inform them before procedures and about further plans regarding discharge. Thus, they did not need to ask a lot of questions and felt safe and assured that things were being taken care of:

'Patient: I get to know what I need without digging and asking...It has been sufficient. And then, when I have got that information, I do not need to bother, or fuss any further about the discharge.' P7 
Although some experienced having their information needs covered, the experiences in relation to information were mostly negative. Several patients and relatives articulated that they did not receive any information if they did not ask for it. Some also experienced difficulties getting relevant information because they did not know what to ask for:

'Well, if I was going to get any information over there, I at last had to ask. I didn't get any information without asking'. R7

'Sometimes they say, "Ask over there," and then there are two of the staff talking to each other and then you don't quite know if you can disturb while they are talking... so if they could just come to us and inform us a little...'. R8

Furthermore, patients also asked for more information about what the plan for the day was instead of having to sit and wait for the doctor to come. Such a lack of timely information made patients feel very confused and impatient:

'It would have been much easier to be here if I had known, instead of sitting here and just waiting... When will someone come and what's next?... It seems like it's all so secret'. P5

Most patients and relatives articulated that it was extremely difficult to get in contact and get information from the doctors because they were always in such a hurry. The relatives frequently experienced having to trust the patient to get informed, which was especially difficult in cases where cognitive impairment was present, and the relatives worried that the patient had not comprehended the information provided:

'It frustrates me more than anything else, not getting answers...not getting in touch with the doctors. I know they have a lot to do, but it's frustrating as a relative. Especially if you have a patient with cognitive impairment'. R9

These experiences of extensive waiting and few answers were often related to experiences of unpredictability for both patients and relatives.

For the patient to receive adequate information, the health personnel also had to be aware of the patient's prerequisites for processing information. Even though many patients experienced getting information, they also conveyed that they could not always remember what they had been told. Relatives expressed that the patient received too much information, and they often did not remember any of it and ended up believing that something completely different was wrong with them. The relatives also highlighted the value of having one responsible doctor, which they described as highly important for patients with cognitive impairment.

'I experience that the treatment becomes so diffuse, that one doctor decides one thing and then another doctor comes and he decides something else, and then a third doctor decides a third thing. You see, there are too many "cooks", and my dad is getting completely confused, he does not understand anything of it'. R4 
The patients also desired involvement in decision-making regarding treatment and discharge, including recognition of their needs. They expressed that early discharge planning provided predictability and promoted hope. However, patients and relatives often experienced inadequate preparation for discharge and a lack of information from the staff, resulting in experiences of inappropriate care and worries about the time after discharge. This also often led to the impression that the patient was being discharged before finishing their treatment:

'I have an impression that the pressure to get a free bed is so great that when there suddenly were many beds in the corridor, he had to leave the hospital, and then I only get a phone call that he had to be picked up in an hour'. R10

\section{Collaboration with relatives}

Both patients and relatives highlighted the importance of involving the relatives throughout the hospital stay. The relatives experienced responsibility for the patients both during the stay and after discharge. However, experiences varied in terms of feeling sufficiently involved in the care of the patient. The relatives explained that the patients depended on them to help them convey their needs. Relatives who were satisfied with the hospital stay expressed that they were included when the patient received information about treatment and discharge planning. They described that they could come to visit whenever they wanted and felt that their knowledge about caring for the patient was valued and considered an asset. In contrast, other relatives felt that they were not heard or taken seriously when they tried to convey the patient's needs. Some relatives almost felt guilty as they felt that the personnel communicated that the relative had the patient admitted for no reason. Furthermore, some relatives also experienced visiting the patient as problematic and did not feel welcome outside the visiting hours:

'They were so set on the rules of visiting time ...they were a bit brusque. He received good care, and I will not complain about that, but somehow when we understood that he would not make it, we found it a bit painful not to get to visit him if we came a little outside visiting hours'. R11

In particular, relatives of patients with cognitive impairment often perceived themselves as an important resource for the care, but they sometimes experienced that their concerns were not taken seriously:

'They would have had to put a person on him "as a stamp" if I had not been allowed to be there. But ... many [of the staff] do not understand. They probably really look at me as someone who wants to get in the way'. R12

Several relatives were worried about leaving the patient alone in the hospital because they perceived that the patient could not speak for him/herself. They doubted that the staff would understand and have enough time to give appropriate care to the patient. The relatives felt that they had to take responsibility so that the patient got the care s/he needed:

'We experience that ...... at least some of us must be there all the time and make sure that he gets what he should get and that he gets the right medication and that he gets it at the right time'. R13

Page $11 / 21$ 
As described in the previous theme, relatives wanted to be involved when information was given and not just read the discharge papers afterwards. One relative suggested a note to relatives about what had been done with the patient during the hospital stay, the diagnosis and how they were expected to follow up after discharge. Both relatives and patients experienced this as reassuring, as the patients themselves often felt unable to perceive everything that was said and were afraid of forgetting things. The relatives highlighted the importance of being involved in the discharge planning process and being assured that the patients' basic needs would also be taken care of after discharge, e.g., by communicating with home care services. However, they often experienced poor or insufficient communication and involvement at discharge, sometimes resulting in negative consequences when the patient returned home. Several relatives perceived that older patients often do not want to be dependent on or a burden for others, thereby saying no when asked if they need help at home. The relatives emphasised that health personnel should verify with the relatives if what the patient was saying about managing at home actually fits the reality:

'They had asked Dad if he needed any help when he got home, but Dad said: "No, no, it's fine, because my daughter does not live very far away!" Things that he knows I somehow do not have the opportunity to do. And then the nurses just rely on this. Well, in this case, this was not true, so it was problematic when he returned home. They should have called and asked if it was true; your father says that when he comes home it's easy for you to help him in the morning and just take time off from work... is that part of reality?'. R14

\section{Discussion}

By interviewing acute hospitalised elderly patients and relatives about their experiences and what they highlighted as important for them during the hospital stay, we found that experiences of security, being respected and experiencing predictability fostered positive experiences. The stories of the patients and relatives tell us that these experiences are related to four main dimensions: 1) being seen and valued as a person, 2) individualised care, 3) patient-adapted communication and information and 4) collaboration with relatives.

Few previous studies have looked at both patients' and relatives' experiences of a specific hospital stay. Comparing their experiences, we see that their perspectives on what is important for a good hospital stay are very similar. A prominent feature in this material is the variation between the positive and negative experiences-from those who were very satisfied and experienced being respected, receiving adequate information and having involvement of relatives to those who experienced dissatisfaction through experiencing the opposite. The experiences were located along a continuum between these extremes. Exploring the reported experiences in further detail, we see that they are not primarily about the lack of care but more about the way care is conducted. We identified three overall factors that seemed to influence the experiences: a) the way healthcare professionals communicate, b) the competence of the health personnel and c) the health personnel's working conditions. In the following, these will be further explored. First, there was high consistency between the patients' and relatives' stories with regard to the 
importance of being met with respect and not being treated as a commodity. Several respondents pointed out the large variation in how one was met by the individual health worker, and that the communication often was task-oriented or diagnosis-focused rather than holistic and individualised. A multisite study by Godfrey et al. (32) described various aspects of patient communication that may influence the patient's experience of respect and dignity. According to Godfrey et al., health personnel often must prioritise medical and other important tasks. However, the way they communicate with the patient when carrying out the tasks is decisive in how the patient experiences being met. As Godfrey et al. (32) advocate, the content of the communication may well be task-oriented, but the form may still be warm and respectful. Through that, the health personnel engage with the patient and communicate at an emotional level. Not only does this help a patient hold on to his or her sense of self; it may also provide trust between nursing staff and patients and allow for individualised care (33). To provide individualised care, it has been highlighted that health personnel must gain knowledge of the patients' normal health condition, including their physical, psychological, cognitive and social functioning and their interests and values, and use this in the communication and care $(32,33)$. Such holistic care has been a key aspect of person-centred care (PCC) (34), which is considered ideal and necessary in the care for older patients with cognitive impairment $(35,36)$. However, most research on the implementation of PCC has focused on long-term care $(37,38)$, and there is no consensus regarding the important features of PCC in other contexts (39). Delivering PCC in acute care settings has been shown to be challenging because of an often task-focused approach, busy environments and fast-paced working conditions (40).

Getting to know the person in the sense PCC requires may be difficult in an acute care setting, and Yevchak et al. emphasised the need to talk with family members to gain such knowledge (33). In this study, some relatives reported disappointment with health personnel for not seeking their opinion about the care of the patient. The relatives often considered themselves to be experts in the care needs of their relatives and therefore wanted to be involved in the planning to be assured that the relative would get the care he/she needed. This is in line with other studies (21). Other reasons for patients and relatives to emphasise family involvement might be that older patients often authorise family members to act and participate on their behalf (41). Findings from several studies underline that health personnel also need to consider the needs of the relative as the informal carer and the dynamics of the relationship between the patient and the relative to individualise the patient's care $(21,41-43)$. In addition to the importance of emotional communication, results from this study also highlight the need for providing factual information, understood as information about treatment and diagnosis, routines for the day and further plans after discharge. For the factual information to be patient-adapted, there is also a need to gain knowledge of the patients' habitual state regarding cognitive or sensory impairment as well as information on what matters for the patient and how the family may be involved to the benefit of the patient (43).

However, gaining knowledge of the patient's habitual state and situation outside the hospital and providing adapted communication and information may be difficult, as nurses in acute care settings report being too busy and lacking time to provide adequate care (33). Health personnel describe time pressure as ubiquitous in the daily care of older persons, leaving them with a sense of failure in terms of 
providing care (44). This means that the reported variation in how the patients and relatives are being met by the health personnel cannot be explained by looking only at the personal characteristics of the individual nurse. The findings must also be interpreted in light of the working conditions that health professionals often describe as physically hard, emotionally demanding and stressful with competing priorities $(32,44)$. Thus, the respondents' frustration at not being seen and heard may, in part, be explained by the reported bustle and hurry in acute medical wards (32), which leaves psychosocial care for patients as a secondary concern (45). Thus, the reported variations between positive and negative experiences may also be indirectly affected by the health personnel's working conditions. This may also indicate a need for changing the clinical mindset and developing ways to integrate recognition of the patient in the hospital routine practice (46) and to ensure that the nursing service in acute care hospitals has the necessary resources to provide the comprehensive care that elderly patients need. Moore et al. advocate that strong leadership and adaptive strategies are important for overcoming existing practices and adapting to traditional hospital care to person-centred care (47). Findings by Alhalal et al. also show that lower burnout, higher compassion, satisfaction and structural empowerment increase nurses' provision of PCC (48).

The variations between positive and negative experiences may also be influenced by the ward culture and knowledge about care for elderly patients. It has been reported that care for patients may be compromised due to low knowledge about cognitive impairment among acute hospital staff (49). Good care for older people requires comprehensive competence (50). This may include advanced practice nurses with special training in geriatric care who can conduct comprehensive assessments and plan and support the care of older people with complex needs. As Henni et al. advocate, organisational adjustments are needed for advanced geriatric nurses to utilise their knowledge and skills to their full potential (51).

\section{Implications for clinical practice}

The study has contributed to a greater understanding and awareness of how elderly patients and relatives experience an acute hospital stay. It contributes important learning points for acute medical wards, where small but important organisational adjustments can be made for each older patient to feel seen, safe, respected and valued as a person. The wards need to be organised in a way that gives healthcare professionals an opportunity to use more of their clinical expertise in complex care for elderly patients. Health personnel must be given time to collect baseline information on the patient to be able to adjust their communication and information in relation to various sensory impairments and cognitive impairments. They also must take into account that elderly patients often need more time to both express their thoughts and receive information. Furthermore, it is the responsibility of the hospital leaders to create a culture where both the guiding values and resource allocation are focused on person-centred communication and care with both patients and relatives.

\section{Strengths and limitations}


The results of this study must be interpreted in light of the relatively short interviews with the informants; thus, we have not received in-depth information in all the interviews. Furthermore, we only captured the perspectives of patients and relatives, but not the health personnel. On the other hand, 58 interviews with both patients and relatives is a large sample and captures a broad variety of experiences. The patient interviews were conducted during the hospital stay and not retrospectively, which is a strength that may have allowed us to capture many experiences and feelings that might later have been forgotten. Even though the sample in this study represents only two medical wards at one hospital, it is a large university hospital with a large admission area. Some of the interviews were performed by the two authors jointly, which provides a common understanding of the interviews. Furthermore, through the analyses, both authors reviewed the data in several rounds to ensure that we agreed on the interpretation of the content. The researchers' different backgrounds-NMW's experiences with clinical practice and MK's experiences with qualitative research methods-have hopefully strengthened the design of the study by bringing supplementary perspectives to the topic at hand and by challenging and/or corroborating each other's interpretations.

\section{Conclusion}

The elderly patients and relatives in this study reported that factors contributing to their experiences of predictability, safety and respect were important for them to experience a good hospital stay. The results underscored how small things matter in relation to how we meet and communicate with patients and relatives, listen, get to know their individual values, needs for care and information, and best involve their relatives as the resources they really are and want to be. For healthcare professionals to have the opportunities to provide the care needed by elderly patients, organisational adjustments of working conditions may be needed.

\section{Abbreviations}

ACE: Acute Care for Elders; Cl: Cognitive Impairment

\section{Declarations}

\section{Ethics approval and consent to participate}

Ethical approval for the study was obtained from the local officer for data protection and the Regional Committees for Medical and Health Research Ethics in Norway (Case number: 2018/666), and all methods were performed in accordance with the relevant guidelines and regulations. Informed consent was obtained from all study participants in this project. Participants could refuse (further) participation at any time.

\section{Consent for publication}


Not applicable.

\section{Availability of data and materials}

The dataset generated and/or analysed during the current study is available from the corresponding author by reasonable request.

\section{Competing interests}

The authors declare that they have no competing interests in this work.

\section{Funding}

The study was funded by the National Association for Public Health (52). The funding body had no influence on the analysis or design of the manuscript.

\section{Authors' contributions}

NMW was the primary author and made substantial contributions to the design, data collection, analysis and drafting of the manuscripts. MK was the primary supervisor and contributed substantially with intellectual feedback through the development of the design, data collection and analysis, and review of the manuscript.

\section{References}

1. World Health Organization. Ageing and health [Internet]. Geneva: WHO; 2018 https://www.who.int/news-room/fact-sheets/detail/ageing-and-health. Accessed 15 Sep 2021.

2. Evensen S, Saltvedt I, Ranhoff AH, Myrstad M, Myrstad C, Mellingsæther M, et al. Delirium og kognitiv svikt blant eldre i norske akuttmottak [Translated title: Delirium and cognitive impairment among elderly in Norwegian acute emergency wards]. Tidsskrift for den Norske laegeforening: tidsskrift for praktisk medicin, ny raekke. 2019;2019;139.

3. Bickel H, Hendlmeier I, Heßler JB, Junge MN, Leonhardt-Achilles S, Weber J, et al. The prevalence of dementia and cognitive impairment in hospitals. Deutsches Arzteblatt international. 2018;115(44):733-40.

4. Julieb $\emptyset$ V, Krogseth M, Neerland BE, Watne LO, Wyller TB. Delirium-a common condition associated with negative outcome in the elderly. Norsk epidemiologi. 2012;22(2).

5. Inouye SK, Westendorp RG, Saczynski JS. Delirium in elderly people. Lancet. 2014;383(9920):91122. 
6. Kolanowski A. Delirium in people living with dementia: a call for global solutions. Aging \& mental health. 2018;22(4):444-6.

7. Hubbard RE, Peel NM, Samanta M, Gray LC, Mitnitski A, Rockwood K. Frailty status at admission to hospital predicts multiple adverse outcomes. Age and ageing. 2017;46(5):801-6.

8. Kojima G. Frailty as a predictor of nursing home placement among community-dwelling older adults: a systematic review and meta-analysis. Journal of geriatric physical therapy (2001). 2018;41(1):42-8.

9. Hospital discharges and length of stay statistics. Eurostat Statistic explained. https://ec.europa.eu/eurostat/statistics-explained/index.php? title=Hospital_discharges_and_length_of_stay_statistics\#Average_length_of_hospital_stay_for_inpatients. Accessed 25 sept 2021.

10. Winterton R, Hodgkin S, Clune SJ, Brasher K. Age-friendly care for older adults within rural Australian health systems: an integrative review. Australasian journal on ageing. 2021;40(1):16-34.

11. Tavares J, Santinha G, Rocha NP. Age-friendly health care: a systematic review. Healthcare (Basel, Switzerland). 2021;9(1).

12. Parke $B$, Boltz $M$, Hunter KF, Chambers $T$, Wolf-Ostermann $K$, Adi $M N$, et al. A scoping literature review of dementia-friendly hospital design. The Gerontologist. 2017;57(4):e62-e74.

13. Parke B, Stevenson L. Creating an elder-friendly hospital. Healthcare management forum. 1999;12(3):45-8.

14. Inouye SK. Predisposing and precipitating factors for delirium in hospitalized older patients. Dement Geriatr Cogn Disord. 1999;10(5):393-400.

15. Sinha SK, Bennett J, Ramsden R, Bon J, Chalk T. Delivering improved patient and system outcomes for hospitalized older adults through an Acute Care for Elders Strategy. Healthcare management forum. 2018;31(4):126-32.

16. Hshieh TT, Yang T, Gartaganis SL, Yue J, Inouye SK. Hospital elder life program: systematic review and meta-analysis of effectiveness. The American journal of geriatric psychiatry: official journal of the American Association for Geriatric Psychiatry. 2018;26(10):1015-33.

17. Godfrey M, Smith J, Green J, Cheater F, Inouye SK, Young JB. Developing and implementing an integrated delirium prevention system of care: a theory driven, participatory research study. BMC health services research. 2013;13:341-.

18. Verma J, O'Connor P, Hodge J, Abrams H, Bennett J, Sinha S. Healthcare for the aging citizen and the aging citizen for healthcare: involving patient advisors in elder-friendly care improvement. Healthcare quarterly (Toronto, Ont). 2017;20(1):14-7.

19. Fox MT, Persaud M, Maimets I, O'Brien K, Brooks D, Tregunno D, et al. Effectiveness of acute geriatric unit care using acute care for elders components: a systematic review and meta-analysis. Journal of the American Geriatrics Society. 2012;60(12):2237-45.

20. Jensen AM, Pedersen BD, Olsen RB, Wilson RL, Hounsgaard L. "If only they could understand me!" Acute hospital care experiences of patients with Alzheimer's disease. Dementia (London, England). 2020;19(7):2332-53. 
21. Bloomer M, Digby R, Tan H, Crawford K, Williams A. The experience of family carers of people with dementia who are hospitalised. Dementia (London, England). 2016;15(5):1234-45.

22. Scerri A, Scerri C, Innes A. The perceived and observed needs of patients with dementia admitted to acute medical wards. Dementia (London, England). 2020;19(6):1997-2017.

23. Bridges $\mathrm{J}$, Collins $P$, Flatley $M$, Hope $J$, Young A. Older people's experiences in acute care settings: systematic review and synthesis of qualitative studies. International journal of nursing studies. 2020;102:103469.

24. Prato L, Lindley L, Boyles M, Robinson L, Abley C. Empowerment, environment and person-centred care: a qualitative study exploring the hospital experience for adults with cognitive impairment. Dementia (London, England). 2019;18(7-8):2710-30.

25. Mockford C. A review of family carers' experiences of hospital discharge for people with dementia, and the rationale for involving service users in health research. Journal of healthcare leadership. 2015;7:21-8.

26. Røsvik J, Rokstad AMM. What are the needs of people with dementia in acute hospital settings, and what interventions are made to meet these needs? A systematic integrative review of the literature. BMC health services research. 2020;20(1):723.

27. Moyle W, Bramble M, Bauer M, Smyth W, Beattie E. 'They rush you and push you too much ... and you can't really get any good response off them': A qualitative examination of family involvement in care of people with dementia in acute care. Australasian journal on ageing. 2016;35(2):E30-4.

28. Tronstad O, Flaws D, Lye I, Fraser JF, Patterson S. Doing time in an Australian ICU; the experience and environment from the perspective of patients and family members. Australian critical care: official journal of the Confederation of Australian Critical Care Nurses. 2021;34(3):254-62.

29. Creswell JW, Poth CN. Qualitative inquiry and research design: Choosing among five approaches. Sage publications; 2016.

30. Braun V, Clarke V. Using thematic analysis in psychology. Qualitative Research in Psychology. 2006;3(2):77-101.

31. Tong A, Sainsbury P, Craig J. Consolidated criteria for reporting qualitative research (COREQ): a 32item checklist for interviews and focus groups. International Journal for Quality in Health Care. 2007;19(6):349-57.

32. Godfrey M, Young J, Shannon R, Skingley A, Woolley R, Arrojo F, et al. The Person, Interactions and Environment Programme to improve care of people with dementia in hospital: a multisite study. Health Services and Delivery Research. 2018;6(23).

33. Yevchak A, Fick DM, Kolanowski AM, McDowell J, Monroe T, LeViere A, et al. Implementing nursefacilitated person-centered care approaches for patients with delirium superimposed on dementia in the acute care setting. Journal of gerontological nursing. 2017;43(12):21-8.

34. Morgan S, Yoder LH. A concept analysis of person-centered care. Journal of holistic nursing: official journal of the American Holistic Nurses' Association. 2012;30(1):6-15. 
35. Tay FHE, Thompson CL, Nieh CM, Nieh CC, Koh HM, Tan JJC, et al. Person-centered care for older people with dementia in the acute hospital. Alzheimer's \& dementia. 2018;4:19-27.

36. Manthorpe J, Samsi K. Person-centered dementia care: current perspectives. Clinical interventions in aging. 2016;11:1733-40.

37. Brownie S, Nancarrow S. Effects of person-centered care on residents and staff in aged-care facilities: a systematic review. Clinical interventions in aging. 2013;8:1-10.

38. Rosemond CA, Hanson LC, Ennett ST, Schenck AP, Weiner BJ. Implementing person-centered care in nursing homes. Health care management review. 2012;37(3):257-66.

39. Gyllensten H, Björkman I, Jakobsson Ung E, Ekman I, Jakobsson S. A national research centre for the evaluation and implementation of person-centred care: Content from the first interventional studies. Health expectations: an international journal of public participation in health care and health policy. 2020;23(5):1362-75.

40. van Belle E, Giesen J, Conroy T, van Mierlo M, Vermeulen H, Huisman-de Waal G, et al. Exploring person-centred fundamental nursing care in hospital wards: A multi-site ethnography. Journal of clinical nursing. 2020;29(11-12):1933-44.

41. Nyborg I, Kvigne K, Danbolt LJ, Kirkevold M. Ambiguous participation in older hospitalized patients: gaining influence through active and passive approaches-a qualitative study. BMC nursing. 2016;15(1):50.

42. Jurgens FJ, Clissett P, Gladman JR, Harwood RH. Why are family carers of people with dementia dissatisfied with general hospital care? A qualitative study. BMC geriatrics. 2012;12:57.

43. Nyborg I, Danbolt LJ, Kirkevold M. User participation is a family matter: a multiple case study of the experiences of older, hospitalised people and their relatives. Journal of clinical nursing. 2017;26(2324):4353-63.

44. Dierckx de Casterlé B, Mertens E, Steenacker J, Denier Y. Nurses' experiences of working under time pressure in care for older persons. Nursing ethics. 2020;27(4):979-90.

45. Chan EA, Tsang PL, Ching SSY, Wong FY, Lam W. Nurses' perspectives on their communication with patients in busy oncology wards: a qualitative study. PloS one. 2019;14(10):e0224178.

46. Britten N, Moore L, Lydahl D, Naldemirci O, Elam M, Wolf A. Elaboration of the Gothenburg model of person-centred care. Health expectations: an international journal of public participation in health care and health policy. 2017;20(3):407-18.

47. Moore L, Britten N, LydahI D, Naldemirci Ö, Elam M, Wolf A. Barriers and facilitators to the implementation of person-centred care in different healthcare contexts. Scandinavian journal of caring sciences. 2017;31(4):662-73.

48. Alhalal E, Alrashidi LM, Alanazi AN. Predictors of patient-centered care provision among nurses in acute care setting. Journal of nursing management. 2020;28(6):1400-9.

49. Galvin JE, Kuntemeier B, Al-Hammadi N, Germino J, Murphy-White M, McGillick J. "Dementia-friendly hospitals: care not crisis": an educational program designed to improve the care of the hospitalized patient with dementia. Alzheimer disease and associated disorders. 2010;24(4):372-9. 
50. Bing-Jonsson PC, Bjørk IT, Hofoss D, Kirkevold M, Foss C. Competence in advanced older people nursing: development of 'nursing older people-competence evaluation tool'. Int J Older People Nurs. 2015;10(1):59-72.

51. Henni SH, Kirkevold M, Antypas K, Foss C. The integration of new nurse practitioners into care of older adults: a survey study. Journal of clinical nursing. 2019;28(15-16):2911-23.

52. National Association of Public Health. https://nasjonalforeningen.no/. Accessed 15 sept 2021.

\section{Figures}

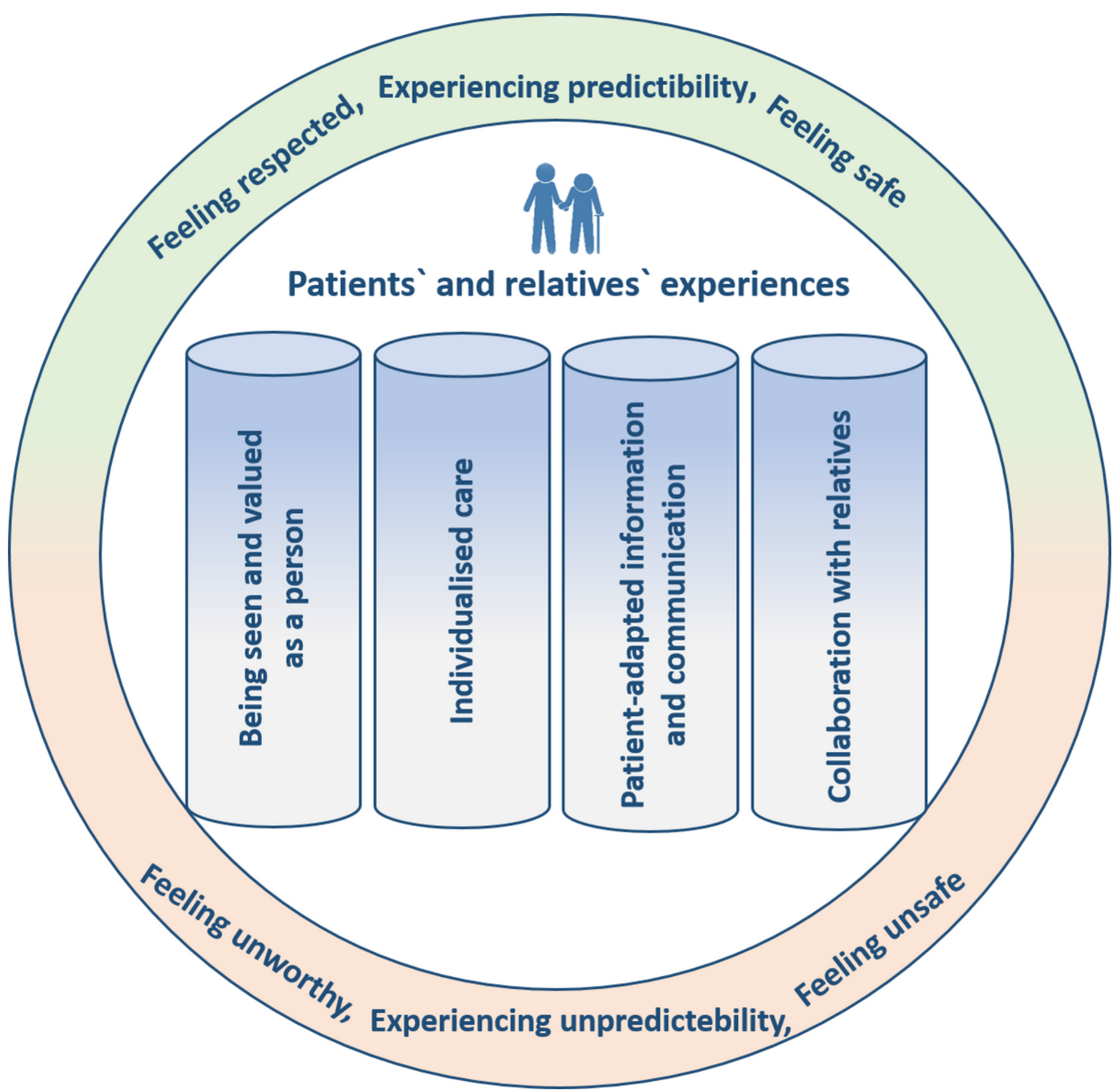




\section{Figure 1}

Important aspects of patients' and relatives' experiences of acute care hospital stay 